\title{
Angioinvasive aspergillosis with halo sign on computed tomography of the lungs
}

\author{
Aspergilose angioinvasiva com sinal do halo na tomografia \\ computadorizada dos pulmões
}

Patricia Moreno Sebastianes ${ }^{1}$, Manuel Fortes ${ }^{1}$ and Gustavo Souza Portes Meirelles ${ }^{1,2}$

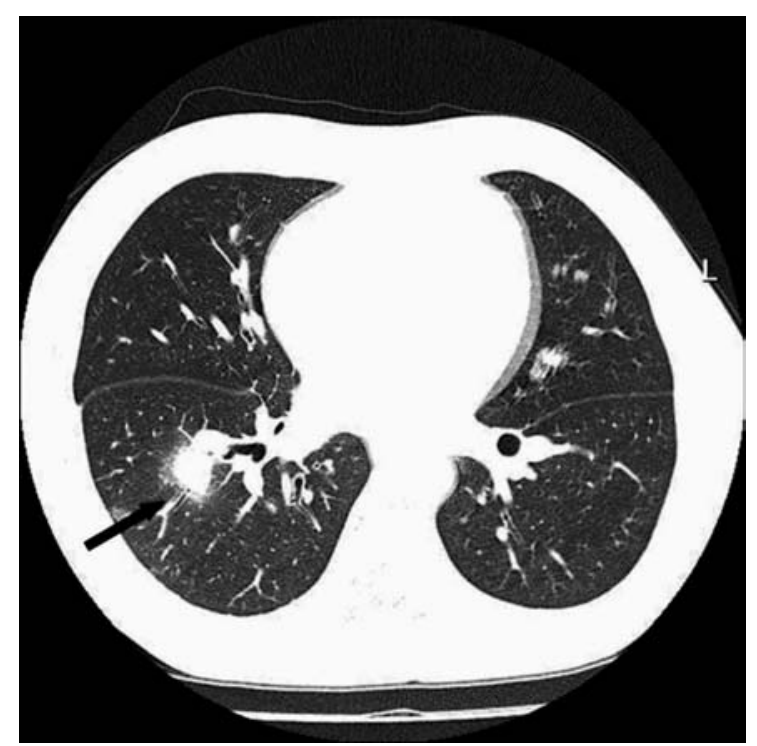

A

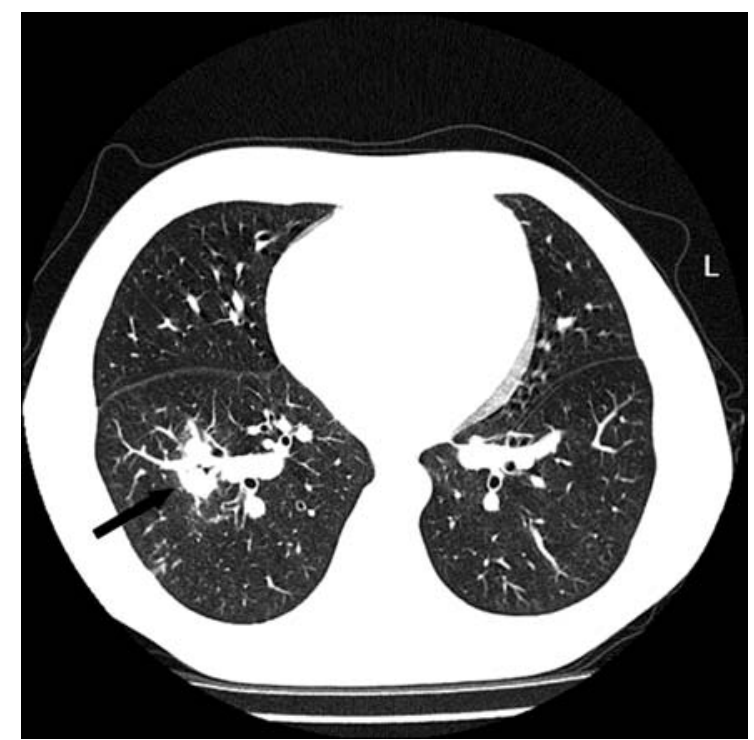

B

1. Departamento de Diagnóstico por Imagem, Escola Paulista de Medicina, Universidade Federal de São Paulo, São Paulo, SP. 2. Centro de Medicina Diagnóstica Fleury, São Paulo, SP.

Address to: Dr. Gustavo de Souza Portes Meirelles. Alameda Itu 78/1404, Cerqueira César, 01421-000 São Paulo, SP. Tel: 5511 8350-9120; $55115014-6806$

e-mail: gmeirelles@gmail.com

Recebido para publicação em: 29/10/2007

Aceito em: 10/03/2008 
A 26-year-old male patient with lymphoblastic T-cell lymphoma in the chemotherapy consolidation phase $\left(13^{\text {th }}\right.$ week $)$ who was using ARA-C/mitoxantrone presented a condition of feverish neutropenia. He underwent high-resolution chest computed tomography (CT), which depicted a pulmonary nodule in the lower right lobe, with the halo sign (Figure A). Pulmonary sputum culturing showed Aspergillus hyphae growth. A control CT scan after ten days of treatment with intravenous amphotericin-B demonstrated a reduction in nodule size and disappearance of the halo sign (Figure B). Chest radiography in angioinvasive aspergillosis cases is usually nonspecific, with multiple illdefined nodular opacities. CT scans may show nodules with the characteristic halo sign. This sign is composed of a ground-glass halo that surrounds a denser central nodule. The central nodule corresponds to a septic infarct, while the halo corresponds to the presence of a hemorrhage.

0 paciente de 26 anos, com linfoma linfoblástico de células T, na fase de consolidação da quimioterapia ( $13^{a}$ semana), em uso de ARA-C/mitoxantrone, apresentou quadro de neutropenia febril. Ele foi submetido à tomografia computadorizada (TC) do tórax de alta resolução, que evidenciou um nódulo pulmonar com o sinal do balo no lobo inferior direito (Figura A). Na cultura de escarro pulmonar, houve crescimento de hifas de Aspergillus. A tomografia computadorizada de controle, após 10 dias de tratamento com anfotericina-B intravenosa, evidenciou redução das dimensões do nódulo e desaparecimento do sinal do balo (Figura B). A radiografia de tórax na aspergilose angioinvasiva é geralmente não específica, com múltiplas opacidades nodulares mal definidas. Na tomografia computadorizada, podemos observar nódulos com o característico sinal do halo. Este sinal é composto por um halo de vidro fosco que circunda um nódulo central mais denso. 0 nódulo central corresponde a um infarto séptico e o halo a presença de hemorragia.

\section{REFERENCES}

1. Franquet T, Muller NL, Giménez A, Guembe P, de la Torre J, Bagué S. Spectrum of pulmonary aspergillosis: histologic, clinical and radiologic findings. Radiographics 21: 825-837, 2001.

2. Gotway MB, Dawn SK, Caoili EM, Reddy GP, Araoz PA, Webb WR. The radiologic spectrum of pulmonary aspergillus infections. The Journal of Computed Assisted Tomography 26: 159-173, 2002.

3. Marchiori E, Valiante PM, Souza Jr AS. Nódulos com sinal do halo na aspergilose pulmonar angioinvasiva: correlação da tomografia computadorizada de alta resolução com a anatomopatologia. Radiologia Brasileira 35: 195-198, 2002. 